\title{
CULTIVO DE Physalis angulata EM DIFERENTES CONCENTRAÇÕES IÔNICAS DA SOLUÇÃO NUTRITIVA
}

\author{
$\underline{\text { Alismário Leite }}$; Romeu da Silva Leite ${ }^{2}$; Tamara Torres Tanan ${ }^{3}$; Lenaldo Muniz \\ de Oliveira ${ }^{4}$ e Marilza Neves do Nascimento ${ }^{5}$ \\ 1. Bolsista PIBIC/CNPq, Graduando em Agronomia, Universidade Estadual de Feira de Santana, e-mail: \\ alismarioagronomo@hotmail.com.br \\ 2. Participante do projeto, Graduando em Agronomia, Universidade Estadual de Feira de Santana, e-mail: \\ leiteromeu@ hotmail.com \\ 3. Participante do projeto, Programa de Pós-Graduação em Recursos Genéticos Vegetais, Universidade Estadual de \\ Feira de Santana, e-mail: tamara.tanan@yahoo.com.br \\ 4. Orientador, Departamento de Ciências Biológicas, Universidade Estadual de Feira de Santana, e-mail: \\ lenaldo.uefs@gmail.com \\ 5. Co-orientador, Departamento de Ciências Biológicas, Universidade Estadual de Feira de Santana, e-mail: \\ marilzaagro@hotmail.com
}

PALAVRAS-CHAVE: hidroponia; nutrição mineral; taxa de crescimento.

\section{INTRODUÇÃO}

A espécie Physalis angulata L., pertencente à família Solanaceae, é uma frutífera nativa do Brasil e amplamente utilizada na medicina popular, sendo alvo de diversos estudos químicos e farmacológicos, principalmente devido à presença de esteróides denominados fisalinas (TOMASSINI et al., 2000). Assim como grande parte das plantas medicinais, a Physalis angulata é obtida através da coleta no seu habitat natural, principalmente quando a espécie possui características multiusos, comprometendo a sobrevivência da espécie no ambiente (ALAMINO, 2011). Estudos sobre o cultivo da espécie são escassos (TANAN et al., 2013) e são utilizadas as recomendações para a cultura do tomate.

Recentemente foi demonstrada a eficiência no cultivo de $P$. angulata em sistema hidropônico (LEITE et al., 2017). Nesse sistema, a espécie vegetal, as fases de desenvolvimento da cultura e o ambiente possuem grande influência na absorção dos nutrientes. Elevada concentração iônica na solução nutritiva pode dificultar a absorção de água pelas plantas, provocando estresse hídrico, e influenciar no crescimento vegetal. Em contra partida, a utilização de baixas concentrações de solução podem causar uma relativa diminuição no teor de massa seca e na qualidade da produção em algumas espécies (LORENZO et al., 2003).

O conhecimento das exigências nutricionais da espécie trabalhada é indispensável para definição da concentração a ser utilizada. Desta forma, objetivou-se nesse trabalho avaliar o crescimento de plantas de Physalis angulata sob diferentes concentrações iônicas da solução nutritiva em cultivo hidropônico.

\section{MATERIAL E MÉTODOS OU METODOLOGIA (ou equivalente)}

O experimento foi conduzido na Unidade Experimental Horto Florestal, pertencente à Universidade Estadual de Feira de Santana (UEFS), Feira de Santana, Bahia. As sementes foram semeadas em bandejas de polietileno, utilizando-se como substrato areia lavada. Quando as mudas apresentaram em média $10 \mathrm{~cm}$, foram transplantadas para vasos de $6 \mathrm{~L}$ contendo solução nutritiva. Utilizou-se o delineamento experimental em blocos inteiramente casualizados com dez repetições, utilizando-se 3 concentrações iônicas da solução nutritiva de Sarruge (50\%; 75\% e 100\%).

As avaliações do crescimento foram realizadas aos 40 dias após o transplante (DAT), utilizando-se quatro plantas por tratamento definidas de forma aleatória. Foram avaliados os seguintes parâmetros: altura da planta; comprimento da raiz; diâmetro do 
caule e a área foliar (AF), mensurada com um integrador de área (Li- Cor, modelo Li3100C). Foi determinada a massa fresca (MF) das folhas, caule e raiz. Em seguida, o material vegetal foi acondicionado e transferido para estufa, para determinação da massa seca (MS). A partir dos dados de MS e AF oi calculada a razão de área foliar (RAF), área foliar especifica (AFE) e a razão de peso foliar (RPF). Os dados obtidos foram submetidos à análise de variância com significância $(\mathrm{P}<0,05)$ e será realizado o teste de médias (Tukey 5\%) empregando o programa estatístico SISVAR® 5.3 (FERREIRA 2008).

\section{RESULTADOS E/OU DISCUSSÃO (ou Análise e discussão dos resultados)}

A análise de regressão para as variáveis comprimento da parte aérea e da raiz, diâmetro do caule, área foliar e MS das partes da planta em relação às concentrações iônicas mostrou que o melhor ajuste foi o linear (Figura 2). A redução da concentração de sais proposto na solução de Sarruge (1975) para $75 \%$ e $50 \%$ não influenciou no comprimento da raiz, no diâmetro da base do caule, nem no acúmulo de MS da raiz e do caule, entretanto a maior concentração utilizada (100\%) proporcionou maior comprimento da parte área e da área foliar, bem como incremento em MS das folhas e consequentemente a MS total (Figura 2). Valores baixos de concentração iônica podem indicar uma disponibilidade abaixo da faixa considerada ótima para o crescimento da espécie (Grattan \& Grieve, 1999), o que diminui o crescimento, como observado neste experimento através da menor MS total em plantas cultivadas a $50 \%$ da concentração onde o nutriente com a menor concentração exigida pela planta pode ter limitado seu desenvolvimento. Resultados similares foram anteriormente observados por Andriolo et al. (2002) e Portela et al (2012) para morangueiro.

As mudanças na absorção de água e nutrientes, proporcionadas pela variação da condutividade elétrica do meio nutritivo, levam a alterações da fisiologia das plantas. Essas alterações relacionam-se, entre outros fatores, à abertura estomática e ao aumento ou diminuição da área foliar, estando esses fatores intimamente relacionados à eficiência fotossintética, e consequentemente, à produção de material seco pelas plantas (Li, 2000).

Para os índices fisiológicos também não foram observadas diferenças entre os tratamentos (Figura 3). A razão de peso foliar representa o quanto à planta investiu da sua produção fotossintética na constituição da matéria seca de suas folhas, e foram semelhantes entre as três concentrações avaliadas (Figura 3A). A área foliar específica, também não apresentou diferença significativa entre os tratamentos utilizados (Figura 3A). A razão de área foliar obtida para as plantas cultivadas a $50 \%, 75 \%$ e $100 \%$ foi de $68,7,71,41$ e $83,71 \mathrm{~cm}^{2} \cdot \mathrm{g}^{-1}$, respectivamente, não apresentando diferença estatística. A RAF representa a área foliar disponível para a fotossíntese, e apesar da maior área foliar observada no tratamento com $100 \%$ da concentração, também houve maior incremento em folhas, o que pode ocasionar o auto-sombreamento, reduzindo assim a área fotossinteticamente útil (BENINCASA, 2003) (Figura 3C). 

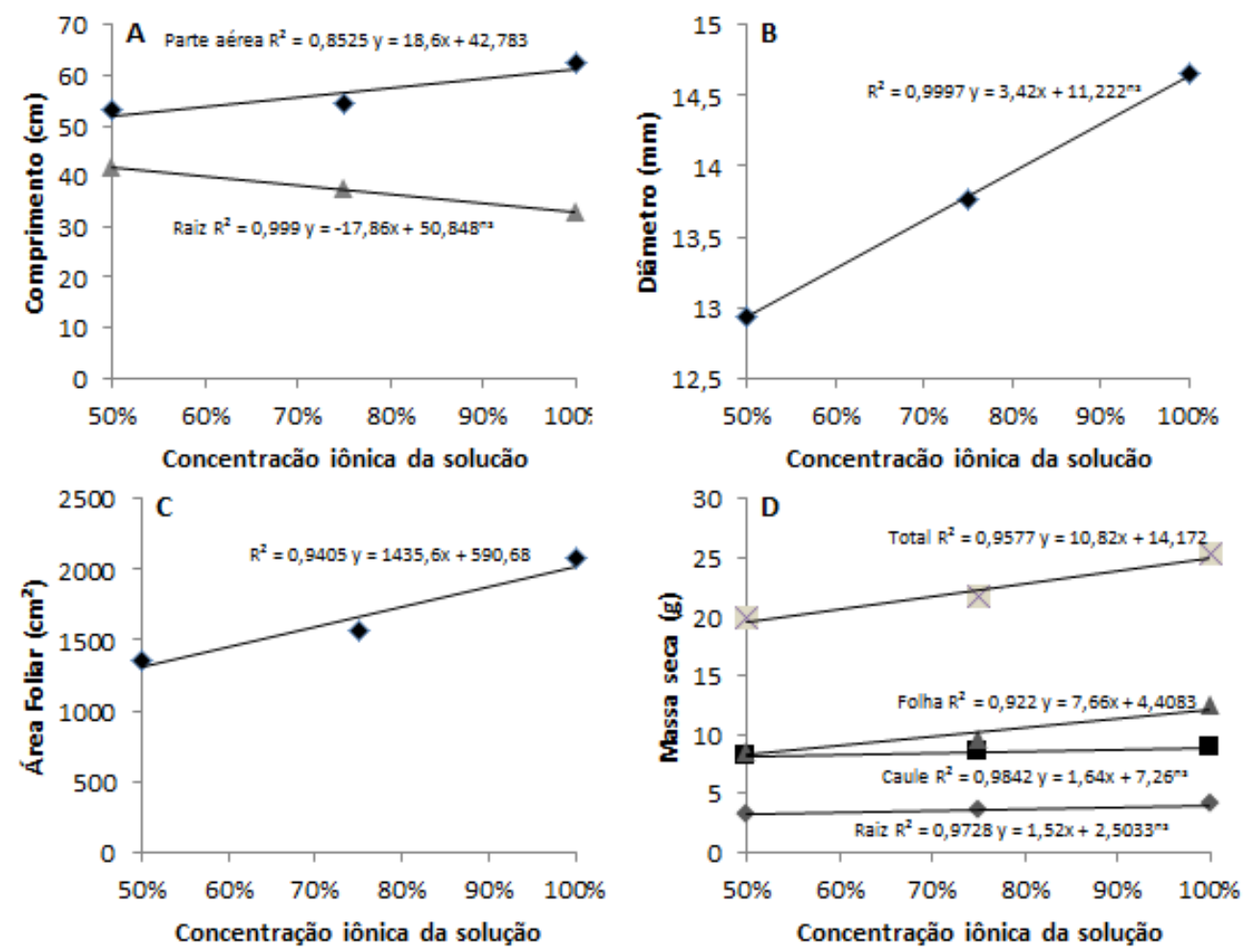

Figura 2. Comprimento da parte aérea e da raiz, diâmetro do caule, área foliar e massa seca da raiz, caule, folhas e total das plantas de $P$. angulata L. cultivadas sob três concentrações iônicas da solução nutritiva.

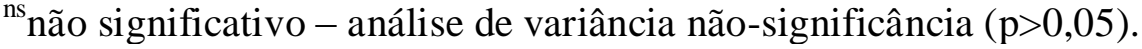
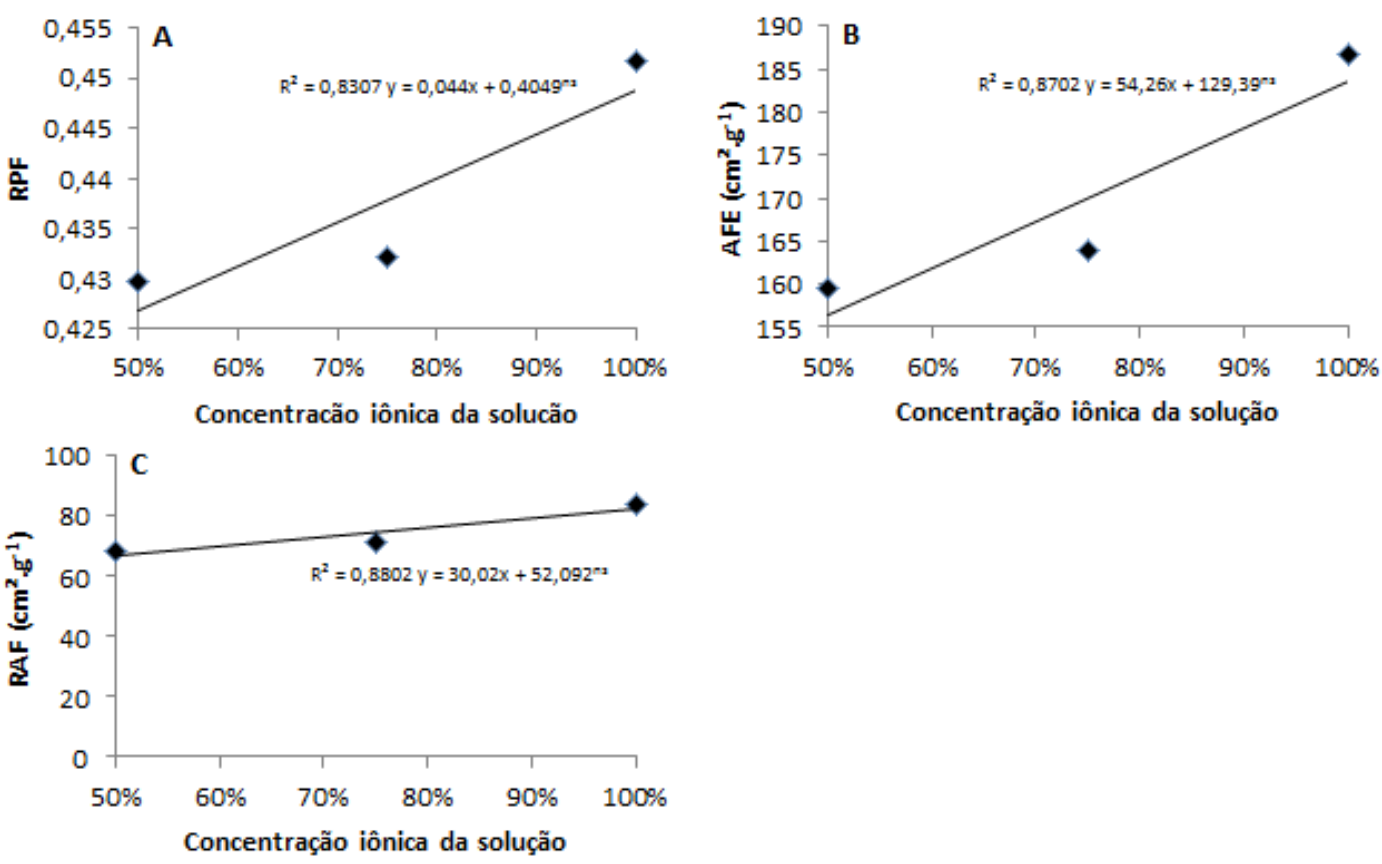

Figura 3 - Razão do peso foliar (RPF), área foliar específica (AFE) e razão de área foliar (RAF) de plantas de Physalis angulata cultivadas em sistema hidropônico sob três concentrações iônicas da solução nutritiva.

${ }^{n s}$ não significativo - análise de variância não-significância ( $\left.p>0,05\right)$.

\section{CONSIDERAÇÕES FINAIS (ou Conclusão)}

A variação da concentração iônica da solução nutritiva não afetou $o$ comprimento e o peso da raiz, o diâmetro do caule, nem os índices físiológicos. 
Entretanto a utilização de $100 \%$ da concentração de sais aumentou a altura da planta, a área foliar e o acúmulo de massa nas folhas.

\section{REFERÊNCIAS}

ANDRIOLO JL; BONINI JV; BOEMO MP. 2002. Acumulação de matéria seca em frutos de morangueiro cultivados em substrato com diferentes soluções nutritivas. Horticultura Brasileira 20: 24-27.

ALAMINO, D. A. Características agronômicas de fisalis (PhysalispubescensL) produzida por diferentes métodos e substratos e aspectos anatômicos e fitoquímicos. Dissertação (Mestrado) - Universidade Tecnológica Federal do Paraná. Programa de Pós-Graduação em Agronomia. Pato Branco/PR, 2011.

BENINCASA, M.M.P. Análise de crescimento de plantas: noções básicas. Jaboticabal: FUNEP, 2003. 41p.

FERREIRA, D. F. Sisvar: um programa para análise e ensino de estatística. Revista Symposium, v.6, p. 36-41, 2008.

GRATTAN SR; GRIEVE CM. 1999. Salinity-mineral nutrient relations in horticultural crops. Scientia Horticulturae 78: 127-157.

LEITE, R. S.; TANAN, T. T.; NASCIMENTO, M. N.; OLIVEIRA, L. M.; ABREU, P. A. S. Hydroponic cultivation of Physalis angulata L.: growth and production under nitrogen doses. Pesq. Agropec. Trop., Goiânia, v. 47, n. 2, p. 145-151, Apr./Jun. 2017.

LORENZO, P. SÁNCHEZ-GUERRERO, M. C.; MEDRANO, E.; GARCÍA, M. L.; CAPARRÓS, I.; GIMÉNEZ, M. External greenhouse mobile shading: effect on microclimate, water use efficiency and yield of a tomato crop grown under different salinity levels of the nutrient solution. In: PARDOSSI, A. et al. (Ed.). Managing greenhou se crops in saline environment. Acta Horticulturae, v.609, p.181-186, 2003.

LI YL. Analisys of greenhouse tomato production in relation to salinity and shoot environment. 2000. (Tese doutorado). Wageningen: Wageningen University. 96p.

PORTELA IP; PEIL RMN; ROMBALDI CV. Efeito da concentração de nutrientes no crescimento, produtividade e qualidade de morangos em hidroponia. Horticultura Brasileira, v. 30, p. 266-273, 2012.

TANAN, T. T.; NASCIMENTO, M. N.; PASSOS, A. R.; LEITE, R. S.; GUIMARÃES, D. S. Physalis angulata L. cultivada sob níveis de adubação NPK. Magistra, Cruz das Almas-BA, v. 25, I RGVNE, nov. 2013.

TOMASSINI, T. C. B.; BARBI, N. S.; RIBEIRO, I. M.; XAVIER, D. C. D. Gênero Physalis: uma revisão sobre vitaesteróides. Química Nova. v. 23. n.1 p. 47-57, 2000.

SARRUGE, J.R. Soluções nutritivas. Summa Phytopathologica, v.1, n.3, p.231-233, 1975. 